\title{
BASOSOH: KOMPOSISI MUSIK ALEATORIC DALAM FORMAT ORKESTRA FLUXUS
}

\author{
Hadi Suhendra $^{1^{*}}$, Martarosa $^{2^{*}}$ Asep Saepul Haris $^{3^{*}}$ \\ Minat Penciptaan Musik Barat Program Pascasarjana \\ Institut Seni Indonesia Padang Panjang \\ Jl. Bahder Johan, Guguak Malintang, Padangpanjang, Kota Padangpanjang, 27126. \\ Sumatera Barat. Indonesia. \\ Email: anggamozaik675@gmail.com
}

\begin{abstract}
Abstrak
Basosoh merupakan karya seni bunyi yang terinspirasi dari fenomena ritual Tabuik di Pariaman Sumatra Barat. Basosoh merupakan kata sifat yang frontal, biasanya diungkapkan dengan berbagai media seperti permainan musik, mengguncang atau mengarak benda seperti Tabuik dengan meneriakan kata Sosoh. Seiring berkembangnya teknologi, Tabuik di tengah-tengah masyarakat telah terkontaminasi oleh desakan otonomi daerah, desakan pariwisata dan otoriter pemerintah yang lebih menggairahkan untuk menunjang sektor kepariwisataan. Posisi dan tujuan untuk pariwisata telah menjadikan Tabuik berubah dari 'ritual' menjadi sekuler. Adanya sekularitas masyarakat secara sadar menyadari perubahan (transformasi) terhadap nilai, fungsi dan makna dalam ritual Tabuik. Berlatar belakang dari transformasi ritual Tabuik, pengkarya terinspirasi untuk menciptakan sebuah karya musik Aleatoric dengan memakai teknik komposisi avant garde serta teknik tradisional musik Barat seperti Canon, imitasi, repetisi dan sekuen. Metode penciptaan dilakukan dengan beberapa pengelompokan kerja: Metode Pengembangan Konsep (Observasi, Wawancara, Pengumpulan Data, dan Perumusan Konsep); dan Metode Mewujudkan Konsep (Eksplorasi, Eksperimentasi, dan Aplikasi). Dalam penggambaran ekspresi zeitgeist ritual Tabuik, karya komposisi musik ini dibuat dalam bentuk tiga bagian berbeda, yang masing-masing diberi judul: Ago, Oyak dan Sosoh. Selanjutnya karya komposisi ini disajikan dengan harapan agar mengetahui, menyadari dan mengkritisi peristiwa budaya masyarakat Pariaman serta memberi tawaran musik baru dalam setiap prosesi upacara Tabuik.
\end{abstract}

Kata Kunci: Basosoh,Tabuik, Aleatoric, Orkestra, Fluxus.

\begin{abstract}
Basosoh is a sound artwork inspired by the phenomenon of Tabuik ritual in Pariaman, West Sumatra. Basosoh is a frontal adjective, usually with various media such as music games, shaking or parading objects like Tabuik by shouting Sosoh. Along with the development of technology, Tabuik in the midst of the community has been contaminated by the insistence of regional autonomy, the pressure of the government and the authoritarian government which is more exciting to support the tourism sector. The position and purpose to make Tabuik change from 'ritual' to secular. The existence of society's secularity, especially towards changes (changes) in values, functions and meanings in the Tabuik ritual. Set from a change in ritual of Tabuik, a visual masterpiece to create an Aleatoric music by using avant garde techniques and traditional music techniques such as Canon, imitation, repetition and sequences. The method is done with several work groupings: Observation Method, Interview, Data Collection, and Concept Formulation); and Conceptualizing Methods (Exploration, Experimentation, and Applications). In describing the zeitgeist Tabuik ritual expressions, this musical composition work is made in the form of three different parts, each of which is entitled: Ago, Oyak and Sosoh. Furthermore, these tasks are carried out in ways to find out, and criticize Pariaman cultural events and provide new tasks in each Tabuik ceremony procession.
\end{abstract}

Keywords: basosoh, tabuik, aleatorik, orchestra, fluxus.

\section{PENDAHULUAN}

Modernitas dan Westrenitas telah melahirkan suatu syndrome "kehampaan eksistensial". Syndrome ini ditandai oleh kebosanan, kehampaan, ketiadaan tujuan, dehumanisasi masyarakat, dan ketidakpedulian dengan apa yang akan dilakukan dalam hidup. "kemauan akan arti" memfokuskan pada pencarian makna bahwa menjalani hidup dimaksudkan untuk suatu tujuan tertentu. Motivasi utama dari setiap individu adalah untuk menemukan tujuan itu, yaitu 


\section{Gorga Jurnal Seni Rupa \\ Volume 07 Nomor 02 \\ p-ISSN: 2301-5942 | e-ISSN: 2580-2380}

bahwa makna dan nilai-nilai ada dalam setiap situasi dan bahwa kita bebas dan bertanggung jawab untuk menemukannya. Pencarian makna yang dilakukan merupakan fenomena kompleks yang membutuhkan penggalian. Untuk memahaminya kita harus "menjalaninya". Setiap individu memiliki peran unik yang harus diperankan, suatu peran yang tak dapat digantikan oleh orang lain. Tugasnya ialah memahami bahwa tidak pernah ada seorang pun yang serupa dirinya.

Ketidak serupaan ini diwujudkan dalam ruang-ruang bunyi. Setiap ruang memiliki waktu yang kompleks, dimana realitas bunyi dimainkan dalam garda masingmasing. Berakar dari spiritual tradisional kultur pantai Barat Sumatra luhak rantau Minangkabau (Ritual Tabuik), menjadi tempat cikal bakal hadirnya budaya hibrid yang hari ini digelar secara sekuler. Sekularitas tersebut menjadi alienasi-diri dan menjadi objek material dalam penggarapan karya Basosoh: Komposisi Aleatoric dalam Format Orkestra Fluxus.

Kenyataan hari ini sebagai daerah Minangkabau, di Pariaman keberadaan Tabuik dapat dilihat dari eksistensinya di tengah-tengah masyarakat telah terkontaminasi oleh desakan otonomi daerah, desakan pariwisata, dan otoriter pemerintahan. Sejak era 1980an, perayaan Tabuik digairahkan untuk menunjang sektor kepariwisataan di Pariaman. Posisi dan tujuan untuk pariwisata tersebut telah menjadikan Tabuik menemukan jati diri barunya dari 'ritual' menjadi sekuler.

Sekularitas telah menjadi identitas bagi masyarakat Pariaman dalam berbagai kegiatan, seperti pesta perkawinan, sunatan, maulid nabi dan pergelaran Tabuik. Secara gotong royong dalam konteks pergelaran Tabuik telah terjadi pergeseran nilai dan makna pada masyarakat sebagai pelaksana Tabuik dan masyarakat sebagai penikmat Tabuik. Pergeseran tersebut terjadi dimana nilai jual lebih diutamakan dari pada nilai esensial. Merujuk pada program Pariwisata yang menjadikan budaya Tabuik sebagai objek wisata yang menjanjikan, dalam bentuk 'komersialisasi' budaya lokal. Sebagaimana Populeritas yang dinyatakan oleh Yasraf Amir Piliang bahwa "Sebuah ruang dalam kebudayaan, yang didalamnya ada kedustaan yang dikemas semenarik mungkin menjadi kebenaran. Ditampilkan lewat teknik pencitraan yang sempurna" (Y. Amir Piliang, 2003:37).

Merujuk pada masa sebelumnya yaitu pada masa tahun 1980-an Tabuik dilaksanakan atas kemauan masyarakat pendukungnya secara gotong royong untuk mencarikan material Tabuik dan mengerjakannya secara bersama-sama. Namun setelah Tabuik masuk anggaran APBD pada tahun 2010, hal ini tidak dirasakan lagi, karena pemikiran masyarakat pada umumnya sudah tersugesti oleh anggaran dari pemerintah, maka totalitas untuk menyumbangkan waktu, tenaga dan fikiran mereka pun juga semakin berkurang (wawancara pada tanggal 20 Februari 2018 di ISI Padangpanjang).

Hal yang demikian juga ditegaskan oleh Syafruddin, bahwa ada beberapa semangat yang berubah dalam pergelaran Tabuik, salah satunya yaitu pada budaya Maradai, yaitu bentuk pencarian dana pembuatan Tabuik yang dilakukan dengan cara meminta sumbangan dari rumah ke rumah sudah tidak dirasakan lagi dibandingkan dulunya. Karena anggaran untuk pelaksanaan Tabuik sudah dianggarkan oleh pemerintah, maka semangat masyarakat untuk menyumbangkan dana mereka pun berkurang (wawancara pada tanggal 11 Maret 2018 di Pariaman).

Berdasarkan dari paparan diatas yang menjadi fokus pengkarya terhadap fenomena tersebut yaitu pada 'sistem komersialisasi' budaya yang dibangun oleh struktural adat dan pemerintahan yang berdampak pada semangat masyarakat dalam memaknai pergelaran Tabuik dewasa ini. Oleh karena sistem tersebut pengkarya melihat alienasi budaya Tabuik terhadap budaya Pop pada masyarakat Pariaman.

\section{KAJIAN TEORI}

Teori yang digunakan dalam penciptaan karya ini ialah teori Alienasi dan teori musik Aleatoric. Sebagaimana Hegel mendefenisikan istilah Alienasi menjadi dua pengertian. Pengertian pertama sebagai 'pemisahan' dan pengertian kedua sebagai 'penyerahan'. Pemisahan atau keterpisahan menurut Hegel bahwasanya hilangnya Independensi yang terjadi ketika seseorang menjadi tergantung pada orang atau hal lain demi mendapatkan sarana, dimana orang tersebut dapat menuai Independensi dan mengembangkan Individualitasnya. Hal yang asing bagi kesadaran diri tersebut adalah eksistensi Independen itu sendiri, dalam keadaan tersebut kesadaran diri merasakan dirinya teralienasi (Richard Schacht, 2016:58). Sedangkan Alienasi dalam pengertian kedua yaitu 'penyerahan' atau 'pengorbanan' dari 'diri' yang ekstensif dan fundamental yang berhubungan dengan 'ditinggalkannya eksistensi independen' dan bahkan 'pelepasan personal' (2016:67). Artinya Hegel membedakan independensi yang mengabaikan 


\author{
Gorga Jurnal Seni Rupa \\ Volume 07 Nomor 02 \\ p-ISSN: 2301-5942 | e-ISSN: 2580-2380
}

peningkatan partikularitas menuju Universalitas antara individu dan substansi sosial.

Selain dari teori Alienasi, pengkarya memakai teori musik Aleatoric yang melibatkan penggunaan elemen peluang dalam penciptaan yang digagas berdasarkan lempar dadu. Sebagaimana Philip Eugene Rush dalam Disertasinya menerangkan bahwa Istilah "aleatoric," secara harfiah ialah "menurut dadu," berlaku untuk semua musik bagi sebagian orang sejauh ini, karena sistem notasi modern tidak mampu mengekspresikan setiap aspek realisasi suatu komposisi, Pengecualian yang mungkin adalah musik yang ditulis dalam bahasa komputer, meskipun jenis musik ini tunduk pada teknis dan pertimbangan akustik (Philip Eugene Rush, 2004:34).

Sebagaimana Pieta Hextall mengatakan dalam Tesisnya Aleatoric merupakan sebuah teknik penciptaan komposisi musik yang lahir pada tahun 1960 di Eropa Barat. Teknik ini mengacu pada unsur kebetulan yang digagas oleh komposer dalam komposisinya, mengharuskan para pemain untuk berkontribusi dalam penyajiannya. Kontribusi pemain tersebut sering disebut sebagai improvisasi, tetapi dalam konteks musik Aleatoric, para pemain berimprovisasi sesuai dalam koridor aturan yang dibuat oleh komposer. Aturan tersebut bersumber dari durasi, tempo, ekspresi dan dinamika. Diluar itu pemain bebas mengekspresikan apa yang dimaksudkan komposer dalam konsep musikalnya (Pieta Hextall, 2012:85).

Pada proses penciptaan karya komposisi musik Basosoh digagas dengan konsep Alienasi dimana Alienasi diartikan sebagai keterasingan makna, nilai dan esensial dalam konteks 'spirit' masyarakat dalam menggelar Tabuik. Dimana pengkarya melihat masyarakat dalam melaksanakan Tabuik di Pariaman dilatar belakangi oleh embel-embel upah. Artinya, prosesi Tabuik yang dilaksanakan masyarakat hari ini tidak lagi murni dari diri masyarakatnya, melainkan karna ada faktor dorongan yang kuat untuk memenuhi kebutuhan materi.

\section{METODE PENCIPTAAN}

Bambang Sunarto menyatakan bahwa metode penciptaan berkaitan dengan aspek formal, yaitu aspek sifat keteraturan susunan artistik yang melekat dalam karya seni yang hendak dicipta dan dapat menjadi karakter pembeda sehingga menjadi karakter istimewa. Metode penciptaan meliputi dua tahap (1) metode untuk mengembangkan konsep, dan (2) metode untuk mewujudkan konsep (Bambang
Sunarto, 2013:87). Berdasarkan metode penciptaan yang dikemukakan Bambang Sunarto pengkarya dalam proses penciptaan karya musik ini melakukan pendekatan metode penciptaan konsep yaitu:

\section{Karya Pengembangan Konsep}

Karya musik Basosoh ini melalui metode pengembangan konsep dilakukan sebuah observasi, wawancara, pengumpulan data sejarah Tabuik dan materi musikal sebagai konsep musikalnya. Materi musikal yang dijadikan sebagai identitas budaya Tabuik pada masyarakat Pariaman adalah kesenian tradisi "Gandang Tambua dan Tasa". Observasi dilakukan untuk melihat dan berkomunikasi langsung dengan masyarakat Pariaman dan sekitarnya, agar dapat deskripsi umum serta informasi lebih lengkap tentang ritual Tabuik. Observasi dilakukan dengan cara berkomunikasi langsung dengan masyarakat yang terlibat langsung dalam proses pembuatan Tabuik maupun pemain Gandang Tambua dan Tasa.

Wawancara dilakukan untuk mencari informasi lebih dalam mengenai upacara Tabuik, diantaranya orang yang memiliki keterkaitan langsung dengan upacara Tabuik baik dari pelaku, penikmat maupun peneliti Tabuik. Informan kunci pada penelitian ini adalah Tuo Tabuik, karena perannya sebagai orang yang dituakan dalam upacara Tabuik untuk mendapatkan informasi tentang fungsi dan pesan dalam upacara Tabuik. Kemudian wawancara dengan masyarakat lokal/penikmat sebagai informan pendukung, untuk mendapatkan informasi lebih mendalam bentuk dan pelaksaan tentang upacara Tabuik. Informasi yang didapat adalah proses pelaksaan upacara Tabuik, pola gendang Tambua serta pesan dan kesan yang ada dalam upacara Tabuik.

\section{Metode Mewujudkan Konsep}

Melakukan eksplorasi bunyi dari instrumen musik konvensional seperti string section dengan mencari kemungkinan-kemungkinan bunyi yang diinginkan. Selain mengeksplorasi bunyi dari instrumen musik konvensional, pengkarya juga melakukan eksplorasi bunyi dari material perkakas sebagai simbol dari pembuatan kerangka Tabuik pada setiap ritus upacaranya Seperti batok kelapa, plat besi, lidi, air, gergaji, pohon pisang dan lain-lain yang diwujudkan pada bagian I dan II.

Melakukan berbagai macam percobaan (eksperimentasi) untuk berbagai kemungkinan yang diperlukan dengan tindakan seleksi material dan respon penemuan bentuk aspek artistik maupun imajinasi dalam mencapai integritas karya Basosoh: 


\section{Gorga Jurnal Seni Rupa \\ Volume 07 Nomor 02 \\ p-ISSN: 2301-5942 | e-ISSN: 2580-2380}

Komposisi Musik Aleatorik dalam format Orkestra Fluxus. Salah satunya melakukan percobaan terhadap material bunyi yang dihadirkan instrumen musik nonmusical dengan pengkolaborasian dengan instrumen musik konvensional. Selain itu, eksperimentasi terhadap simbol notasi yang tidak umum.

Pemilihan beberapa materi musikal yang telah dirancang, disempurnakan untuk kemudian diaplikasikan menjadi materi hasil akhir karya dan dalam proses aplikasi yang dilakukan tentunya mengalami perkembangan dan perubahan-perubahan terhadap rancangan sebelumnya sesuai dengan konsep dan proses kreatif yang melibatkan intuisi dalam pengolahan aspek musikal serta improvisasi yang diekspresikan kedalam graphic score yang dituliskan pada notasi karya.

\section{HASIL DAN PEMBAHASAN}

Alienasi-diri masyarakat terhadap sistem komersialisasi yang menjadi sumber inspirasi maka pengkarya menggagas komposisi musik Basosoh dengan memakai teknik Aleatoric dimana Alienasidiri diartikan sebagai keterasingan makna, nilai dan esensial dalam konteks 'spirit' masyarakat dalam menggelar Tabuik. Maka dari itu karya ini diberi judul Basosoh: Komposisi Musik Aleatoric dalam format Orkestra Fluxus, dengan sub judul Ago pada bagian I, Oyak pada bagian II dan Sosoh pada bagian III. Serta ide musikal dalam karya ini diambil dari motif permainan musik tradisional Pariaman yaitu gandang tambua dan gandang tasa dengan repertoar hoyak tabuik dan repertoar maatam.

Konsep musik dari judul diatas adalah konsep Musik Aleatoric dalam format Orkestra Fluxus. Konsep komposisi ini merupakan pemanfaatan dari lempar dadu / koin, mengambil kartu dari topi, untuk menentukan bagaimana potongan musik yang akan disusun (Griffiths, 1981:47). Komposer memiliki kesengajaan dengan memegang kendali dalam permainan musik. Sebagian besar komposisi tak tentu jatuh dalam tiga kategori umum; (1) penggunaan operasi peluang dalam asal-usul tetap komposisi, (2) penyisihan pilihan-pilihan tertentu yang harus dibuat oleh pemain di antaranya beberapa opsi yang disediakan oleh komposer, dan (3) penggunaan metode notasi yang mana kurangi kontrol komposer atas suara yang dihasilkan oleh pemain.

Hal tersebut didukung oleh Pieta Hextall dalam Tesisnya yang menyatakan istilah Aleatoric merupakan sebuah teknik penciptaan komposisi musik yang lahir pada tahun 1960 di Eropa Barat. Teknik ini mengacu pada unsur kebetulan yang digagas oleh komposer dalam komposisinya, mengharuskan para pemain untuk berkontribusi dalam penyajiannya. Kontribusi pemain tersebut sering disebut sebagai improvisasi, tetapi dalam konteks musik Aleatoric, para pemain berimprovisasi sesuai dalam koridor aturan yang dibuat oleh komposer. Aturan tersebut bersumber dari durasi, tempo, ekspresi dan dinamika. Diluar itu pemain bebas mengekspresikan apa yang dimaksudkan komposer dalam konsep musikalnya (Pieta Hextall, 2012:85).

Dieter Mack (2009:559) istilah Fluxus merupakan salah satu aliran yang tidak mempunyai batasan estetis tertentu. Sesuatu yang berhubungan dengan kategori seni maupun yang berhubungan dengan hal diluar seni. Fluxus mencabut diri dari sebuah pendekatan ilmiah dan rasional. Peristiwa seni yang berdasarkan ide Fluxus hanya bisa dialami secara 'Live' atau langsung. Untuk itu dalam karya Basosoh ini pengkarya menghadirkan bentuk Fluxus sebagai pendukung media interpretasi dalam karya komposisi ini.

Musik Aleatoric disisi lain melibatkan penggunaan elemen peluang dalam penciptaan yang digagas berdasarkan lempar dadu. Untuk mendapat ide melodisnya dadu dilempar dengan memberi penomoran dalam setiap wilayah nada. Nada dalam setiap masing-masing wadah berupa serialism yaitu berdasarkan duabelas nada. Nada tersebut diacak dan ketika dadu dilempar, maka nada yang keluar itulah nada yang dipakai dalam penciptaan musik.

Penciptaan musik Basosoh dalam format Orkestra Fluxus di gagas dengan teknik Aleatoric, dimana unsur musikal yang dipakai ialah pola ritmis gandang tambua sedangkan unsur melodis yaitu Aleatoric musik. Unsur musik dari skala harmoni memakai metoda Arnold Schoenbert dimana kebebasan dalam memilih wilayah nada tidak terbatas atau sistem deret dari dua belas nada kromatik, artinya duabelas nada itu boleh digunakan dalam penggarapan komposisi musik. Selain dari itu, teknik komposisi tradisional musik Barat diantaranya ialah canon, repetisi, sekuen dan imitasi.

Ide musikal karya ini berasal dari kesenian tradisi Pariaman yaitu Gendang Tambua dan Tasa. Ide tersebut bersumber dari tiga hal; (1) pola gendang tambua sebagai wujud pelahiran untuk menggambarkan fanatik ritual Syi'ah dalam

\section{Deskripsi Karya}




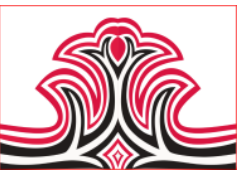

melaksanakan budaya Tabuik; (2) dinamika yang dimainkan pada gandang tambua sebagai bentuk ekspresi perwujudan eksistensi Tabuik pada masyarakat Pariaman, dan; (3) pandangan dan makna dari upacara Tabuik di Pariaman. Ketiga hal ini dikonsep untuk menciptakan pesan dan kesan upacara Tabuik dalam komposisi musik. Pengkarya menjadikan motif instrumen tersebut menjadi graphic score. Adapun bentuk motif dari gandang tambua dan tasa tersebut ditransformasi dari salah satu reportoar Hoyak Tabuik, dimana repertoar tersebut merupakan repertoar wajib dalam mengiringi Tabuik. Berikut contoh motif repertoar Hoyak Tabuik yang dimainkan gandang tambua dan gandang tasa.

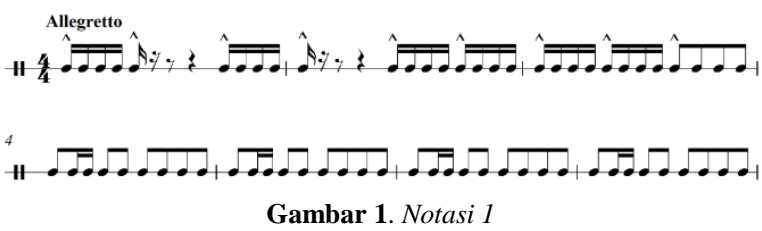

Motif Hoyak Tabuik yang dimainkan Gandang Tasa.

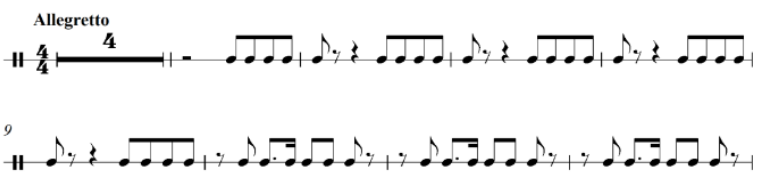

Gambar 2. Notasi 2

Motif Hoyak Tabuik yang dimainkan Gandang Tambua.

Motif tersebut diolah dengan memakai teknik; (1) Precompositional and Random Operation yaitu pengambilan putusan dari dadu yang dilempar digunakan dalam pembuatan nada dalam komposisi baru. Nada yang telah dirandom yaitu Dis-E-F-G-GisA. (2) Improvisation Box yaitu wilayah improvisasi pemain terhadap graphic score yang dibaca. (3) Work Section yaitu memainkan pesanan yang terdapat dalam notasi. (4) Graphic Score yaitu notasi yang dibuat oleh komposer sendiri dengan ketentuan-ketentuang yang dijelaskan dalam keterangan dan (5) Completely Verbal Score yaitu wilayah tanpa musik atau wilayah keheningan dalam setiap kalimat musik yang dimainkan.

Pengembangan teknik tradisional musik Barat seperti canon, repetisi, sekuen, imitasi dan lain-lain yang diinterpretasi dalam konsep, alur suasana serta penggunaan instrumen yang dibutuhkan. Untuk itu deskripsi bentuk, konsep, alur suasana, penggunaan instrumen dan bentuk musik pada bagian-bagian karya ini dibagi menjadi tiga bagian besar. Tiga bagian tersebut dapat dilihat pada tabel berikut.
Gorga Jurnal Seni Rupa

Volume 07 Nomor 02

p-ISSN: 2301-5942 | e-ISSN: 2580-2380

Tabel 1.

Penjelasan Alur, Suasana, Bentuk Musik,

Teknik Garap Serta Penggunaan Instrumen

\begin{tabular}{|c|c|c|c|}
\hline $\begin{array}{c}\text { Bagian } \\
\text { (Sub Judul) }\end{array}$ & $\begin{array}{c}\text { Penjelasan Alur, Suasana, } \\
\text { dan Bentuk Musik }\end{array}$ & Penggunaan Instrumen & Teknik Garapan \\
\hline $\begin{array}{c}\text { Bagian I } \\
\text { (Ago) }\end{array}$ & $\begin{array}{l}\text { Konsep alur: } \\
\text { perihal sebab akibat yang } \\
\text { menggambarkan kedatang } \\
\text { awal mula Tabuik yang } \\
\text { dibawa oleh orang Syi'ah. } \\
\text { Konsep suasana: Khidmat, } \\
\text { keras dan patriotik. } \\
\text { Konsep bentuk: } \\
\text { menggunakan bentuk musik } \\
\text { satu bagian. }\end{array}$ & $\begin{array}{l}\text { Banyak menggunakan instrumen } \\
\text { dengan karakter berat, panjang, dan } \\
\text { lamban seperti dalam String Section } \\
\text { (Viola, Violincello, dan C. Bass), } \\
\text { dan Perkusi (Bass drum, timpani, } \\
\text { snare, floor, GTM), Bras section } \\
\text { (trombon, hom, trompet dan tuba) } \\
\text { Serta instrumen musik non } \\
\text { konvensional ialah (plat besi, air, } \\
\text { palu, paku, dan gergaji), serta noise } \\
\text { sound yang dihadirkan media } \\
\text { televisi sebagai back sound dari } \\
\text { komposisi. }\end{array}$ & $\begin{array}{l}\text { Random Operation } \\
\text { dengan } \\
\text { menggunakan } \\
\text { teknik repetisi, } \\
\text { selwen, completely } \\
\text { verbal score, as } \\
\text { hight and low } \\
\text { posible, cluster not, } \\
\text { open and close } \\
\text { glissando, curva } \\
\text { glissando, } \\
\text { indeterminate event, } \\
\text { vibration reguler } \\
\text { serta dinamika fast } \\
\text { and slow cressendo } \\
\text { and decressendo. }\end{array}$ \\
\hline $\begin{array}{r}\text { Bagian II } \\
(\text { Oyak) }\end{array}$ & $\begin{array}{l}\text { Konsep alur: } \\
\text { Prilaku tanpa arah dan } \\
\text { Apatis. Menggambarkan } \\
\text { keterasingan masyarakat } \\
\text { pekerja Tabuik terhadap } \\
\text { pemerintahan pariwisata. } \\
\text { Konsep suasana: }\end{array}$ & $\begin{array}{l}\text { Menggunalcan instrumen yang } \\
\text { memiliki karakter yang ringan, dan } \\
\text { terang. Seperti dalam String } \\
\text { Section (Violin, Viola), Percussion } \\
\text { Section gendang tambua dan tasa, } \\
\text { floor, snare, simbal. }\end{array}$ & $\begin{array}{l}\text { Memakai telknik } \\
\text { workpection, free } \\
\text { glissando, kurva } \\
\text { glissando, equetion } \\
\text { and numeral, smash, } \\
\text { vibration reguler, } \\
\text { cluster not, canon, } \\
\text { serta meemakai }\end{array}$ \\
\hline & $\begin{array}{l}\text { Kacau, bingung, seram, } \\
\text { takut, ngeri, terlena. } \\
\text { Konsep bentuk: } \\
\text { menggunakan bentuk musik } \\
\text { satu bagian. }\end{array}$ & $\begin{array}{l}\text { Bras section (trompet, dan } \\
\text { trombon) Serta instrumen musik } \\
\text { non konvensional ialah (plat besi, } \\
\text { air, perkakas tukang seperti palu, } \\
\text { paku, gergaji, kayu dan bambu), } \\
\text { serta noise sound yang dihadirkan } \\
\text { media televisi sebagai back sound } \\
\text { dari komposisi. }\end{array}$ & $\begin{array}{l}\text { dinamika silent } \\
\text { cressendo dan silent } \\
\text { decressendo. }\end{array}$ \\
\hline $\begin{array}{l}\text { Bagian III } \\
\text { (Sosoh) }\end{array}$ & $\begin{array}{l}\text { Konsep Alur: } \\
\text { Prikemanusiaan, melebur, } \\
\text { suka cita antar sesama } \\
\text { masyarakat. } \\
\text { Menggambarkan Tabuik } \\
\text { Adat yang dibawakan oleh } \\
\text { masyarakat Pariaman. } \\
\text { Konsep suasana: } \\
\text { Kemeriahan, megah, } \\
\text { riang dan bahagia. } \\
\text { Konsep bentuk: } \\
\text { menggunakam bentuk } \\
\text { musik satu bagian. }\end{array}$ & $\begin{array}{l}\text { Menggunakan instrumen gitar } \\
\text { klasik, violin dan syntetizer. } \\
\text { Minimalis agar bervariatif yang } \\
\text { juga menyimbolkan karakter } \\
\text { masing-masing instrument tersebut } \\
\text { terhadap semangat pemainnya. } \\
\text { Seperti syntetizer yang } \\
\text { menyimbolkan pengaruh } \\
\text { digitalisasi masa. Gitar klasik dan } \\
\text { violin sebagai permainan klasik } \\
\text { secara teknisnya. }\end{array}$ & $\begin{array}{l}\text { Banyal memakai } \\
\text { teknik } \\
\text { Indeterminate } \\
\text { Event, worksection, } \\
\text { completely verbal } \\
\text { soore, dan unisono. }\end{array}$ \\
\hline
\end{tabular}

Pada masing-masing bagian dan sub bagian komposisi ini memiliki beberapa teknik Aleatoric berdasarkan suasana yang diinginkan. Adapun teknik yang dipakai pada masing-masing bagian adalah sebagai berikut.

\section{1). Movement I. "Ago"}

Pada bagian pertama diberi judul Ago yang artinya negosiasi yang diinterpretasikan dari asal mula Tabuik yang dibawa bangsa Syi'ah ke Pariaman. Saat bangsa Syia'ah tersebut melaksanakan ritual Tabuik posisi masyarakat lokal masih melirik dari jauh tentang apa yang dilakukan Syi'ah. Pemakaian sub judul ini pengkarya tafsirkan seperti negosiasi budaya. Hal ini juga berhubungan dengan sebab akibat. Secara struktur bentuk, pada bagian ini pengkarya garap dalam musik satu bagian. Pada bagian tersebut menghadirkan kesan sakral yang melankolis dengan tempo lambat.

Bagian pembuka pengkarya hadirkan dengan teknik Indeterminate Event yang dimainkan oleh media water. Teknik ini merujuk pada bagian motif yang diimprovisasi oleh pemain dengan sistem acak. 


\section{Gorga Jurnal Seni Rupa \\ Volume 07 Nomor 02 \\ p-ISSN: 2301-5942 | e-ISSN: 2580-2380}

Improvisasi tersebut diberi instruksi berdasarkan konsep dan pemahaman dengan memakai tempo slowly atau Hymne. Liat contoh notasi 3 di bawah.

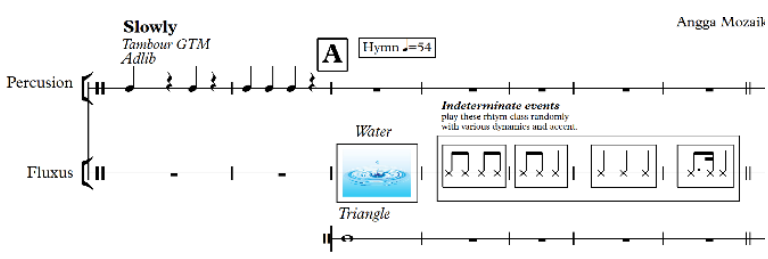

Gambar 3. Notasi 3

Penggunaan teknik indeterminate even yang mengharuskan pemain mengacak motif yang di instruksikan

Pengkarya menghadirkan konsep ritual yang menggambarkan kedatangan awal mula Tabuik yang dibawa oleh Syi'ah. Ide musikal pengkarya transformasi dari motif gandang tambua yaitu repertoar Maatam. Kemudian pengkarya garap dengan memakai teknik precompositional dan Random Operation. Hal ini sangat relevan dalam sumber penciptaan nada pada komposisi ini agar tidak terkesan mengada-ngada. Dadu tersebut dilempar pada dua belas nada kromatik, dimana dadu yang keluar itulah yang jadikan unsur melodik dalam. Sedangkan melodi vokal memainkan melodi dengan teknik whispering (berbisik) agar kesan sakral dan hasutan lebih dapat dirasakan. Lihat notasi 4.

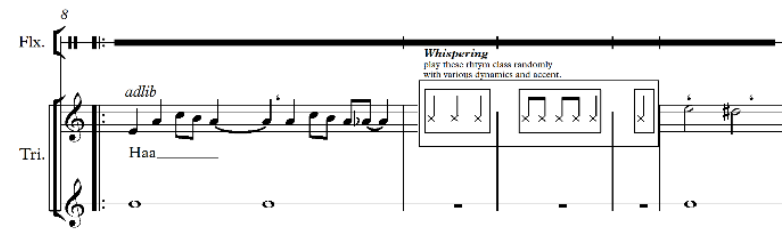

Gambar 4. Notasi 4

Melodi vokal dimainkan dengan teknik whispering yang di random berdasarkan teknik Indeterminate Evant.

Nada yang keluar akan dimainkan oleh instrumen melodis berkarakter low section seperti cello, contrabass, trombon dan horn. Kemudian pada instrumen perkusi yaitu timpani dan grandcassa memainkan motif gandang tambua dengan teknik pengembangan motif augmentasi dan diminusi. Adapun hal lainnya pengkarya memadukan unsur fluxus kedalam garapan tersebut. Pengkarya menghadirkan material besi yang dipadukan dengan air. Material tersebut sebagai efek dengan memakai motif gendang tasa yang akan dimainkan. Tempo yang dimainkan dominan lambat sekitar 50-60. Adapun divisi string seperti violin satu dan violin dua bermain chordal (block chord) dengan teknik harmonic tone.

\section{2). Movement II. "Oyak"}

Bagian kedua 'Oyak' memakai bentuk musik satu bagian, menghadirkan suasana kacau (yang tidak umum didengar) dengan nuansa harmoni chord by second. Oyak diiterpretasikan seperti guncangan yang merefleksikan gejolak batin dari ekspresi personal dalam melihat pergelaran Tabuik Pariaman yang mana diekspresikan sebagai bentuk kekacauan individu dengan diri sendiri dan individu dengan lingkungannya. pengkarya mempresentasikannya dengan memakai metode garapan komposisi Aleatoric yaitu Graphic Score atau notasi yang dipakai bukanlah notasi konvensional seperti not balok pada umumnya, melainkan pengkarya memakai sistem notasi sendiri dalam pembuatan notasi. Berbentuk simbol baru seperti sistem spiral dan dimainkan sesuai dengan interpretasi pemain. Tetapi ada beberapa hakekat yang pengkarya beri instruksi salah satunya dengan menjaga tempo, metter dan dinamika. Sedangkan motif yang dimainkan berupa transformasi dari repertoar maatam/pangka maatam dari gendang tambua. Lihat notasi 5 dibawah.

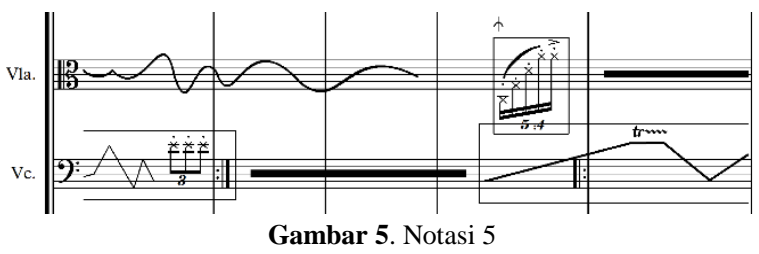

Notasi grafik yang dimainkan sesuai interpretasi pemain. Teknik ini dinamakan dengan Curva Glisando dan Equepmant Numeral.

Adapun dalam penerapan sistem Aleatoric ini, dimainkan oleh instrumen melodis baik itu divisi string, tiup kayu maupun logam. Sedangkan pada instrumen perkusi pengkarya menghadirkan dalam bentuk fluxus yang dimainkan oleh instrumen nonmusical dengan material plat besi, tempurung yang akan pengkarya eksplor dengan memakai pola gandang tambua (permainan dalam material ini berbentuk eksplorasi bunyi) dengan sistem acak atau Indeterminate Event. Selain itu, pengkarya menghadirkan suara nois yang dipresentasikan oleh media telivisi sebagai ambiance atau backsound dalam bagian ini. Menandakan pengaruh digitalisasi budaya yang diawali dari media televisi membuat masyarakat terhanyut, terbuai maupun terlena.

\section{3).Movement III. "Sosoh"}

Bagian ketiga dalam karya ini berjudul Sosoh yang merupakan harapan dalam pemaknaan esensi dari pergelaran Tabuik yang diartikan sebagai sikap kerja keras dan tak mempertimbangkan hal yang bersifat material yaitu sebuah ekspresi masyarakat Pariaman dulunya dalam menggelar Tabuik.

Bagian ini menggambarkan tentang ekspresi masyarakat dalam menggelar Tabuik. Suasana suka 


\section{Gorga Jurnal Seni Rupa \\ Volume 07 Nomor 02 \\ p-ISSN: 2301-5942 | e-ISSN: 2580-2380}

cita diwujudkan dalam bagian ini. Sebagai simbol eksistensi masyarakat dalam menggelar pesta budaya diwujudkan dengan teknik pengolah motif seperti unisono atau seluruh material bunyi digagas dengan teknik Graphic Score, Work Section, Completely Verbal Score dan Improvisation Box. Lihat notasi 6 dibawah.

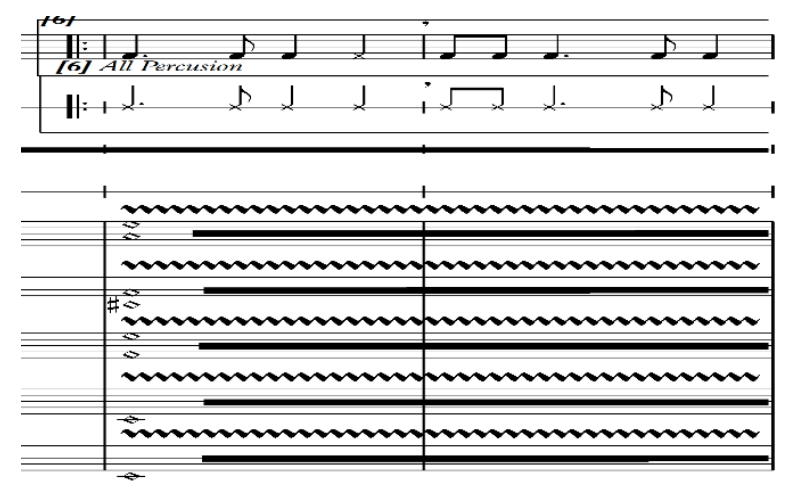

Gambar 6.

Notasi 6 Teknik tradisional musik Barat Unisono dan teknik musik Over Vibra pada section string.

Pada bagian ini menghadirkan seperangkat musik eletronik yang dimainkan oleh komputer dengan suara noise. Nois tersebut di interpretasikan pada perkembangan teknologi yang berdampak terhadap semangat masyarakat dalam menggelar pesta budaya Pariaman. Bagian ini juga menceritakan tentang sebuah perkembangan dan perubahan semangat yang berdampak pada pendidikan masyarakat baik secara langsung maupun tidak langsung. Secara teknis pengkarya menghadirkan seperangkat Televisi sebagai penunjang visual art agar maksud yang ingin disampaikan tercapai. Lihat notasi 7 dibawah.

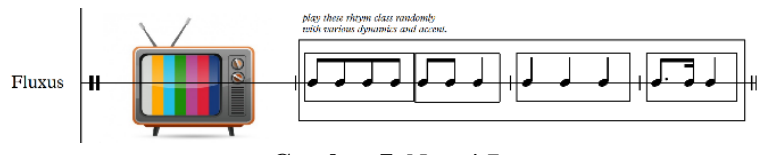

Gambar 7. Notasi 7

Permainan musik elektronik dengan sample suara nois yang dimainkan dengan teknik Indeterminate Event.

Permainan pada notasi diatas jelas bahwa setiap motif yang dimainkan diacak sesuai interpretasi pemain. Motif tersebut dimainkan oleh media musik elektronik dengan sample nois sound yang dihadirkan melalui media televisi. Nois sound tersebut tetap dimainkan sampai bagian coda atau penutup komposisi.

\section{Analisis Karya}

1).Movement I. "Ago"

Sebagaimana musik Avant Garde pada umumnya tidak memakai tema musikal atau tematik. Melainkan esensial bunyi yang menjadi sumber kekuatan sebuah komposisi. Hal ini sangat relevan dalam penciptaan musik yang bersumber dari ritmis gandang tambua sebagai sumber idiom musikal dalam penciptaan karya ini. Sumber musikal tersebut diambil beberapa motif yang kemudian digarap dengan memakai teknik musik Aleatoric. Teknik tersebut digarap dengan menggunakan indeterminate event, work's section, completelly verbal score dan graphic score yang diinterpretasikan oleh pemain dengan media Orkestra Fluxus.

Pagian pertama Ago secara keseluruhan memiliki waktu durasi lima belas menit dengan tujuh bentuk graphic score. Setiap masing - masing transisi pada graphic score diberi wilayah completelly verbal score atau wilayah tanpa musik. Hal ini dimaksudkan untuk memfokuskan pendengar kepada ruang kontemplasi. Diawali dengan permainan gandang tambua yang bermain ad libitum yang berulang, kemudian dilanjutkan oleh permainan media fluxus dengan material air yang di eksplore berdasarkan indeterminate event. Pada graphic score yang pertama dimainkan oleh vokal seriosa dengan menggunakan teknik indeterminate event yang mana vokal mengeksplore melodi tersebut dengan teknik whispering.

Bentuk graphic yang kedua difokuskan pada section string dengan menggunakan teknik bridge, open glisando dan close glisando sedangkan teknik tradisional musik Barat memakai bentuk repetisi dan canon. Pada bagian ini dimainkan oleh full orkestra, section tiup memakai teknik canon dan contrapung 1:4 sedangkan perkusi hanya memainkan beat yang difungsikan sebagai pijakan pemain melodis dalam

Pada graphic ketiga repetisi dari graphic yang kedua dimana pada bagian ini yang bermain hanya section brash dan woodwind tetapi pada instrument gong menggunakan media batu sebagai media pokul dengan cara mengosokkan batu pada sisi gong. Setalah itu vokal kembali dihadirkan dengan teknik yang sama (whispering) yang diirngi dengan media fluxus yaitu batang pisang yang dieksplore dengan teknik indeterminate event.

Bagian coda kembali menghadirkan vokal yang diirngi oleh instrument marimba dengan memainkan dalam wilayah tempo slowly. Sedangkan media fluxus yaitu water kembali hadir sebagai bentuk ekspresi khidmad. Secara keseluruhan pada bagian satu ini banyak menggunakan teknik indeterminate event, completelly verbal score, key slap pada instrument woodwind dan increase pada instrument brass. membaca graphic. 


\section{2).Movement II. "Oyak"}

Pada bagian ini diinterpretasikan sebagai bentuk mengalun, terbang, melambung yang presentasikan dengan permainan curva glissando. Memiliki durasi waktu lima belas menit dengan memakai tempo slowly. Permainan divi string section sangat dominan dalam memainkan grapchic score pada bagian ini. Dikarenakan instrument string mampu mewakili wilayah microtone yang diinginkan. Untuk itu pada bagian ini pengkarya lebih banyak memakai teknik curva glissando. Adapun teknik lain seperti col legno batuto dan indeterminate event masih tetap dipakai sebagai variatif improvisasi yang diacak.

Adapun teknik yang dimainkan oleh brass dan woodwind juga menggunakan indeterminate event dengan nada yang telah diacak berdasarkan lempar dadu diawal bagian. Nada tersebut ialah Dis-E-F-GGis-A. Keseluruhan bagian ini menggunakan wilayah work'section dimana segala bentuk esensial bunyi dituliskan pada lembar score masing-masing partisi pemain.

\section{3).Movement III. "Sosoh"}

Bagian tiga sebagaimana diberi judul Sosoh diinterpretasikan dengan permainan yang sangat ribut. Permainan tersebut dipresentasikan dengan teknik unisono yang mana semua instrument bermain secara bersamaan. Diawali dengan graphic yang dimainkan oleh electro acustic dengan sample nois sound. Sedangkan orkestra bermain motif gandang tambua dengan repertoar Sosoh yang di orkestrasikan ke media Orkestra. Pada bagian ini menggunakan tempo fast (cepat).

Secara keseluruhan pada bagian ini menggunakan dua graphic yang mana pada graphic pertama menggunakan curva glissando yang dimainkan oleh electro acustic, sedangkan pada graphic kedua memainkan teknik equetion numeral. Sosoh yang diiterpretasikan sebagai bentuk sikap sebagai manusia yang abdi pada kebudayaan tradisional yang harus dilestarikan. Pada sikap tersebut pengkarya mencampur adukkan antara permainan secara tradisional dan permainan secara modern yang dipresentasikan pada media electro acustic dan orkestra. Adapun instrument fluxus mewakili sikap tradisional yang bermain secara manual, instrumen seadanya seperti perkakas tukang dan pohon pisang yang dimainkan dengan teknik indeterminate event. Wilayah nada yang dipakai yaitu Dis-E-F-G-Gis-A yang dimainkan secara horizontal maupun vertikal. Dimainkan secara improvisasi pemain dengan random operational tecnic maka harmoni yang dapat dirasakan pada bagian ini yaitu chord by second, M2, dan $m 2$.

\section{KESIMPULAN DAN SARAN}

Komposisi musik dengan judul Basosoh merupakan komposisi yang terinspirasi dari fenomena ritual Tabuik di Pariaman. Bercerita tentang sistem dan semangat sosial masyarakat lokal Pariaman dalam menggelar Tabuik, baik masyarakat sebagai pelaksana Tabuik maupun masyarakat sebagai penikmat Tabuik. Komposisi ini dibagi menjadi tiga bagian yang setiap bagian diberi judul Ago pada bagian satu, Oyak pada bagian dua, dan Sosoh pada bagian tiga. Digarap dengan metoda musik Avant Garde yang memakai teknik Aleatoric serta Orkestra Fluxus yang menjadi media presentasi bunyi. Komposisi ini berdasarkan sebuah ekspresi personal komposer dalam melihat fenomena budaya di Pariaman. Sebagaimana terjadi transformasi perubahan pada ritual Tabuik yang berdampak pada kepudaran semangat masyarakat untuk terlibat pada setiap prosesi upacara. Hal tersebut sangat pangkarya rasakan sebuah alienasi diri dalam melihat pesta budaya Tabuik. Untuk itu pengkarya mempresentasikannya lewat media bunyi. Komposisi musik Aleatoric sebagai teknik dalam menggarap bunyi sangat relevan untuk di presentasikan. Dengan idiom musikal gandang tambua pengkarya hadirkan bentuk-bentuk gagasan bunyi antara ruang dan waktu dalam permainannya. Baik secara teoritik maupun teknis aplikasinya.

\section{DAFTAR RUJUKAN}

Amir Piliang, Yasraf. 2003. Hiper Semiotika Tafsir Cultural Studies Atas Matinya Makna. Jalasutra: Yogyakarta.

Asril. 2016. Tabuik: Pertunjukan Budaya Hibrid Masyarakat Kota Pariaman. Disertasi. Yogyakarta: Pascasarjana Institut Seni Indonesia.

Eugene Rush, Philip. 2004. A String Player's Guide to Improvisation in Western Art Music: Florida State University.

Griffiths, Paul. 2010. Modern Music and After. Madison Avenue, New York: Oxford University Press, Inc.

Griffiths, P. (1981). Modern music: The Avant Garde since 1945. New York: George Braziller. 